\title{
A framework for performing comparative LCA between repairing flooded houses and construction of dikes in non-stationary climate with changing risk of flooding
}

\author{
Hennequin, Thomas; Sørup, Hjalte Jomo Danielsen; Dong, Yan; Arnbjerg-Nielsen, Karsten
}

\section{Published in:}

Science of the Total Environment

Link to article, DOI:

10.1016/j.scitotenv.2018.05.404

Publication date:

2018

Document Version

Peer reviewed version

Link back to DTU Orbit

Citation (APA):

Hennequin, T., Sørup, H. J. D., Dong, Y., \& Arnbjerg-Nielsen, K. (2018). A framework for performing comparative LCA between repairing flooded houses and construction of dikes in non-stationary climate with changing risk of flooding. Science of the Total Environment, 642, 473-484.

https://doi.org/10.1016/j.scitotenv.2018.05.404

\section{General rights}

Copyright and moral rights for the publications made accessible in the public portal are retained by the authors and/or other copyright owners and it is a condition of accessing publications that users recognise and abide by the legal requirements associated with these rights.

- Users may download and print one copy of any publication from the public portal for the purpose of private study or research.

- You may not further distribute the material or use it for any profit-making activity or commercial gain

- You may freely distribute the URL identifying the publication in the public portal 
1 A framework for performing comparative LCA between 2 repairing flooded houses and construction of dikes in 3 non-stationary climate with changing risk of flooding

\author{
4 Thomas Hennequin ${ }^{1}$, Hjalte Jomo Danielsen Sørup ${ }^{1,2}$, Yan Dong ${ }^{2,3}$, Karsten Arnbjerg-Nielsen ${ }^{1,2}$ \\ 5 1: DTU Environment (thhen@env.dtu.dk, hjds@env.dtu.dk, karn@env.dtu.dk) \\ 6 2: DTU GDSI - Global Decision Support Initiative \\ 3. DTU Management Engineering (yado@dtu.dk)
}

Abstract: Sustainable flood management is a basic societal need. In this article, life cycle assessment is used to compare two ways to maintain the state of a coastal urban area in a changing climate with increasing flood risk. On one side, the construction of a dike, a hard and proactive scenario, is modelled using a bottom up approach. On the other, the systematic repair of houses flooded by sea surges, a post-disaster measure, is assessed using a Monte Carlo simulation allowing for aleatory uncertainties in predicting future sea level rise and occurrences of extreme events. Two metrics are identified, normalized mean impacts and probability of dike being most efficient. The methodology is applied to three case studies in Denmark representing three contrasting areas, Copenhagen, Frederiksværk, and Esbjerg. For all case studies the distribution of the calculated impact of repairing houses is highly right skewed, which in some cases has implications for the comparative LCA. The results show that, in Copenhagen, the scenario of the dike is overwhelmingly favorable for the environment, with a 43 times higher impact for repairing houses and only $0 \%$ probability of the repairs being favorable. For Frederiksværk and Esbjerg the corresponding numbers are 5 and 0.9 times and 85\% and $32 \%$, respectively. Hence constructing a dike at this point in time is highly recommended in Copenhagen, preferable in Frederiksværk, and probably not recommendable in Esbjerg. 
26

GIS Geographic information system

LCA Life Cycle Assessment

$\mathrm{LCl} \quad$ Life Cycle Inventory

PE Person Equivalent

RE Relative Efficiency of a dike, either calculated or observed

SLR Sea Level Rise

SR Sensitivity Ratio

$\mathrm{D}_{\mathrm{i}}\left(\mathrm{FD}_{\mathrm{t}, \mathrm{city}}\right) \quad$ Step Damage function of Flood Depth for item $i$ ranging from 0 to 1

$\mathrm{di}_{\text {city }} \quad$ Dike Impact in a city and in a given category

$\mathrm{FD}_{\mathrm{t}, \mathrm{ity}} \quad$ Stochastic variable representing the Flood Depth of year $t$ in a city

$\mathrm{ft}_{\text {city }}$ Flood Threshold, sea water level at which damage starts to occur in a given city

$\mathrm{l}_{\mathrm{j}}\left(\mathrm{FD}_{\mathrm{t}, \mathrm{city}}\right) \quad$ Impact of one flood on house $j$ in year $t$ in a given category

$\mathrm{IQ}_{\mathrm{i}} \quad$ Initial Quantity of an item $i$

Mcity Number of houses flooded at least once during the century for a given city

$\mathrm{N}_{\text {city }}\left(\mathrm{X}_{\mathrm{t}, \text { city }}\right) \quad$ Number of houses flooded for a given sea water level in a given city

TI $I_{\text {city }} \quad$ Total Impact

$\mathrm{UI}_{\mathrm{i}} \quad$ Unitary Impact of a single item $i$ in a given category

$\mathrm{X}_{\mathrm{t}, \text { city }} \quad$ Stochastic variable representing the maximum sea level of year $t$ in a city, including SLR

$\mathrm{Y}_{\text {city }} \quad$ Stochastic variable representing maximum sea level for year $t_{0}$

$Z_{\text {city }} \quad$ Stochastic variable representing SLR 


\section{Introduction}

Ecosystems and human infrastructures in coastal regions are under the constant threat of floods. Accounting for half of the natural disasters' casualties in the world, flooding is amongst the most impactful calamity (Guha-Sapir, 2016). Moreover, Sea Level Rise (SLR) is expected to locally increase the risk and resulting damage of these events. SLR will increase both flood frequency and depth in most of the world, even though the effect is not geographically uniform (Hirabayashi et al., 2013). In the case of northern Europe (Baltic and North Seas), a relative SLR of $80 \mathrm{~cm}$ is expected by the end of the century, with substantial uncertainty (Grinsted et al., 2015; Hallegatte et al., 2013; Reynard et al., 2004). Combined with a growing urban density of inhabitants and infrastructures (UN, 2014), this makes management of flood risk a primary concern for society.

Losses due to flooding affects society in many ways, of which substantial parts are difficult to quantify. Often all losses are monetized, and many studies indicate that effects on the built environment is a substantial part of the overall economic losses (Merz et al., 2010). Amongst the urban landscape, the most heavily affected land uses are residential buildings, commerce and industry which together amount to more than $80 \%$ of the total damage; the remaining fifth covers agriculture and roads (ICPR, 2001). Residential areas eventually rank first (Huizinga, 2007). In combination with the intangible nature of many of the other types of losses, such as traffic or loss of amenity value, the materials used in relation to repairing the built environment in residential areas will therefore constitute the major part of the overall material consumption and is hence the focus of this study.

While a range of technologies exists that protect and mitigate flood risk in coastal cities and more are being developed, the construction of a dike still seems to be the most favored scenario. The feasibility of implementing this type of solution is mostly being assessed using a risk assessment framework where risk is defined as a combination of potential economic damage and probability of occurrence (Morita, 2008). In this study, the analysis is made from an environmental emissions viewpoint, using LCA to compare the impact of the dike's construction and the post-disaster reparation of houses if the dike is not built.

The LCA framework is extensively standardized by ISO 14040 and 14044 (ISO, 2006a, 2006b). It is widely used as a decision tool across multiple fields and even though it is mostly directed towards the assessment of single products, is still highly relevant for larger systems. Several LCAs have been conducted on single family residences as well as on the built environment as an entity (Goldstein et al., 2018; Khasreen et al., 2009; 
Vilches et al., 2016) and on stormwater management infrastructures (Brudler et al., 2016; Flynn and Traver, 2013). In literature, when environmental impact is included in the risk assessment field, which it seldom is, it is done so qualitatively and with rather limited scopes. This is partly due to a lack of policy imperatives when it comes to inclusion of environmental impact assessment in flood risk management (European Commission, 2007). Only a few studies have paired LCA with flood damage and protection assessment. It was done, for example, by assessing flood prevention in the form of infrastructure construction, such as concrete walls and ripraps, while integrating avoided damage (Petit-Boix et al., 2016) or by integrating flood damage prevention into the LCA of a filter, swale and infiltration trench (Petit-Boix et al., 2017). It was also done by including the impact of flood repairs into a residence's LCA in order to study a flood resilient design (Matthews et al., 2016).

The novel approach developed in this study results in conducting a comparative LCA between dike construction and post-flood repairs, an approach not found in other works to the authors' knowledge. The LCA conducted for the dike is comparable to many other comparative LCAs of systems because all uncertainties are in principle epistemic (i.e. reducible by collecting more information). The LCA for flood related repairs however includes a substantial aleatory (i.e. non-reducible) uncertainty because of unknown future amounts of sea-level rise and unknown trajectory of future extreme events. The comparative LCA is hence between a deterministic value and a stochastic variable. We show that these aleatory uncertainties in some case dominate the overall uncertainty and discuss how different statistics of stochastic variable can be used to enable decision makers to take relevant action and prioritize scenarios.

\section{Materials and Methods}

\subsection{Goal and scope}

The goal of this study is to compare the impact of resource consumption for two scenarios: the dike scenario where the hard solution is built, and the post-disaster scenario where flood related repairs in the residential sector are considered instead.

To do so, LCA is used to assess the environmental consequences from both alternatives. A traditional LCA approach would yield deterministic environmental consequences of the flood related repairs. However, the unpredictable nature of storms makes the damage uncertain which is solved by applying a probabilistic approach. A Monte Carlo analysis is used for that purpose and draws samples from distributions of annual maximum water levels allowing for future SLR. This enables an estimation of the distribution of damage levels, and subsequently the mean of the damages. The resulting distributions, means of damages and corresponding impact in different categories are compared to the impact of building the dike, which is found by means of a 
87 traditional LCA. By doing so, the probability of one scenario being more favorable than the other is calculated. Moreover, the dike's relative efficiency is expressed by calculating how many meters of dike that can be constructed per house flooded with the same environmental impact. Finally, the robustness of the model and the influence of the main hypotheses are tested by means of sensitivity analyses.

LCA is an iterative process comprised of four main steps: 1) the goal and scope definition which sets the aim and limitations of the study; 2) the Life Cycle Inventory ( $\mathrm{LCl}$ ) construction listing all unit flows and processes needed to implement the scenario; 3 ) the life cycle impact assessment where the $\mathrm{LCl}$ is converted into impacts in different categories; and 4) interpretation of the results.

An overview of the framework developed is presented in Table 1. Two metrics are defined using the results, which are meant to be used for informing decision-makers regarding which of the scenarios is preferable from an environmental standpoint. These metrics are: 1) comparison of the dike's fixed impact with the mean impacts of flood related repairs, and 2) comparison of the dike's fixed impact with a fitted distribution of the flood related repairs, recognizing that the latter has substantial aleatory uncertainty at the point of decision. The second comparison yields the probability that building the dike has a lower environmental impact than flood related repairs of the residential sector.

While it is intended to describe the aleatory uncertainty inherent to future amounts of sea-level rise and trajectory of future extreme events with the help of a Monte Carlo analysis, the epistemic uncertainty of the traditional side of the LCA is not quantitatively assessed. The authors are aware of existing methods aiming at assessing the uncertainty in input inventory or impact assessment method by propagating the uncertainty to the results (Lo et al., 2005; Mattila et al., 2012). However, here the Monte Carlo analysis deals with the uncertainty linked to decision making instead. 


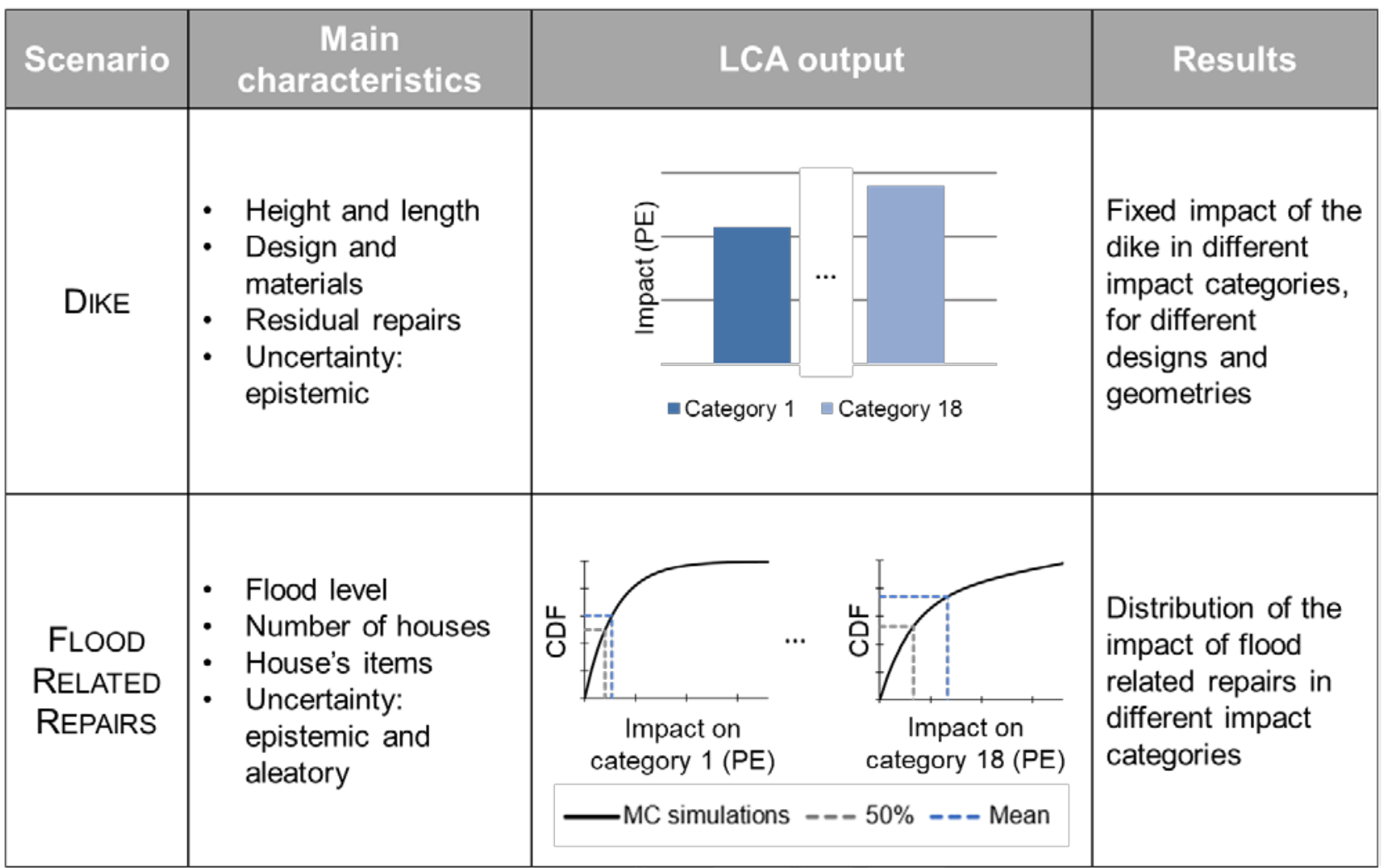

The functional unit to be fulfilled, in either scenario, is to maintain the state of the households on a coastal area, through flooding and SLR, for a century. A timeframe of a hundred years was chosen because it corresponds to both the technical lifetime of the dike as well as the timeframe of the SLR projections. To fulfill that purpose, the system boundaries summarized by Table 2 were drawn with a focus on including the main activities that separate the two scenarios. The result is hence a comparative LCA: the phases excluded must occur irrespectively of whether the dike is constructed or not. In the case of the dike, some stages are excluded because their impact is negligible. In particular, dike overflows are statistically insignificant, occurring for $1.6 \%$ of the simulations in Copenhagen, and less than $0.1 \%$ in Frederiksværk and Esbjerg.

\begin{tabular}{|l|c|c|}
\hline Construction of houses/dike & $\mathrm{X}$ & $\checkmark$ \\
\hline Maintenance of houses/dike (replacement, reparations) & $\mathrm{X}$ & $\mathrm{X}$ \\
\hline Use (heating, electricity, water, etc.) & $\mathrm{X}$ & $\mathrm{X}$ \\
\hline Flood related repairs & $\checkmark$ & $\mathrm{X}$ \\
\hline Demolition of house/dike & $\mathrm{X}$ & $\mathrm{X}$ \\
\hline Recycling of construction materials for houses/dike & $\mathrm{X}$ & $\mathrm{X}$ \\
\hline
\end{tabular}


To assess the impact of flood related repairs, the residential built environment is modelled in the LCA framework, with a priority on elements that will suffer consequences from a flood. Several types of houses can be found in the Danish residential areas and modelling all of them is not feasible. Without loss of generality it is here assumed that flood related repairs can be modelled by considering only one type of building and ignoring all other types of damages. The typical building considered is a standard single-family residence, a $130 \mathrm{~m}^{2}$ house built on a concrete slab with a brick structural frame, a $20 \mathrm{~cm}$ thick mineral insulation and a 120years useful life. A variant on that design will be studied in the assumption check (see section 2.7). Both were modelled using the SimaPro software and follow modern Danish and European standards of construction. A floor plan of the baseline single-family residence can be found in Figure 1a. The house can be divided into 32 items from varied categories such as flooring, insulation, plumbing, etc. (Hennequin et al., n.d.), although any environmental assessment of a house could have fit in the framework. An initial quantity, $I Q_{i}$, was calculated for each item $i$ which is the initial amount needed when building the house.

A hybrid dataset of LCls was used to model the items constituting the single-family residence, following the attributional approach. Whenever available, specific environmental product declarations were used, either from Oköbaudat (FME, 2016) or INIES (INIES, 2017). While this is the most representative data accessible, it is not always available, and the results declared are often obscure (limited number of impact categories, vague LCls). This specific dataset was thus completed using SimaPro's generic data (Ecolnvent, etc.). Therefore, this LCA uses a process based, bottom-up approach. The ReCiPe midpoint method is used for impact assessment, delivering results in its 18 impact categories (Goedkoop et al., 2013). Once modelled, a unitary impact, $U I_{i}$, was calculated for each item $i$ in each impact category.

\subsection{Modelling dikes}

For the second scenario, the dike was modelled in the LCA framework by combining the knowledge of a field visit in Avedøre, Copenhagen, and of two guidelines (DPWH and JICA, 2010; MARD, 2011). This lead to the design condensed in Figure $1 \mathrm{~b}$, with a cover made of $10 \mathrm{~cm}$ of asphalt and $10 \mathrm{~cm}$ of reinforced concrete and a useful life of a century which was the design criteria of the functional unit. This design was used for the three case studies although both the length and height were adjusted to fit the local geographical situation. The impact of the dam in a given city is denoted $d i_{c i t y}$. 


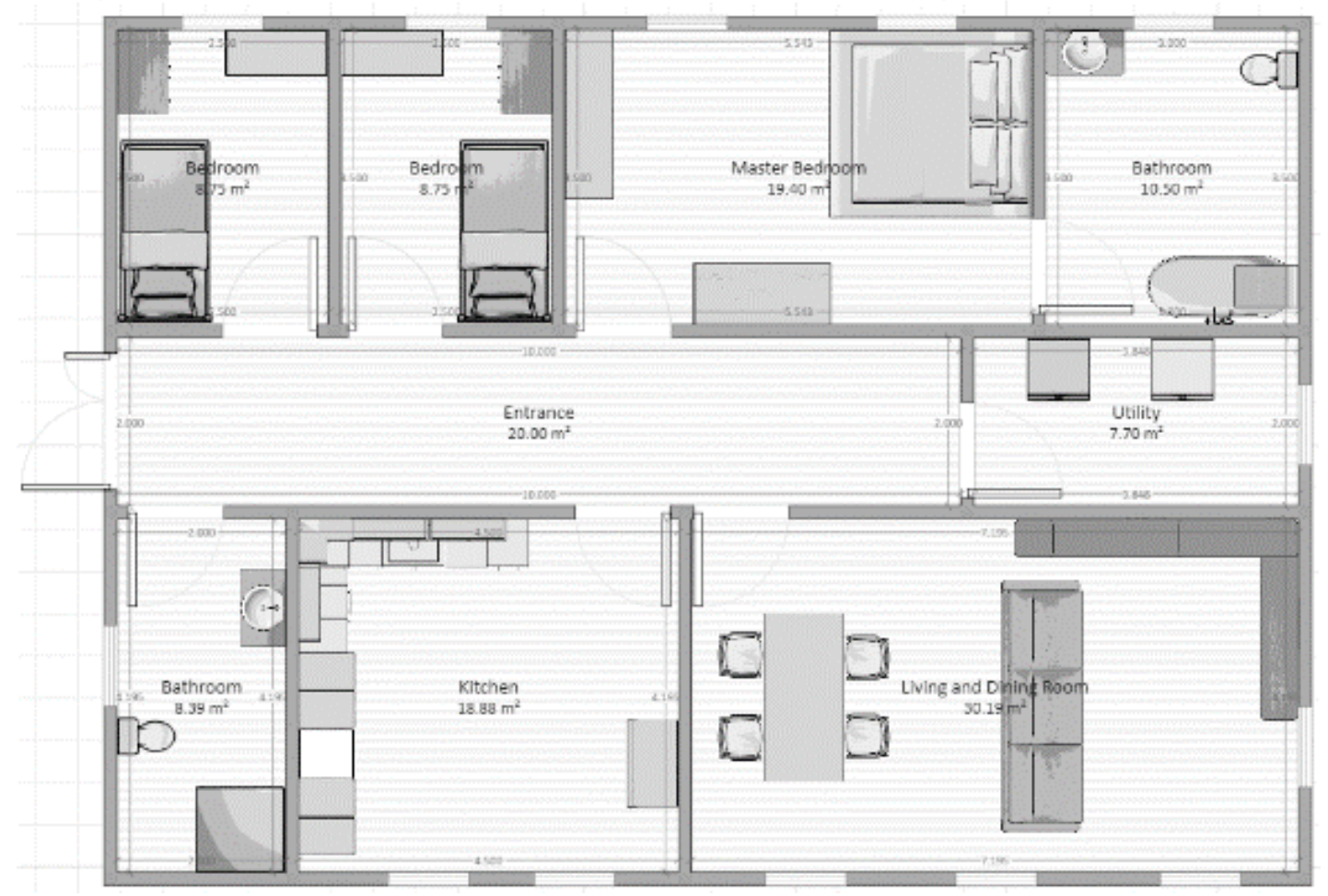

(a)

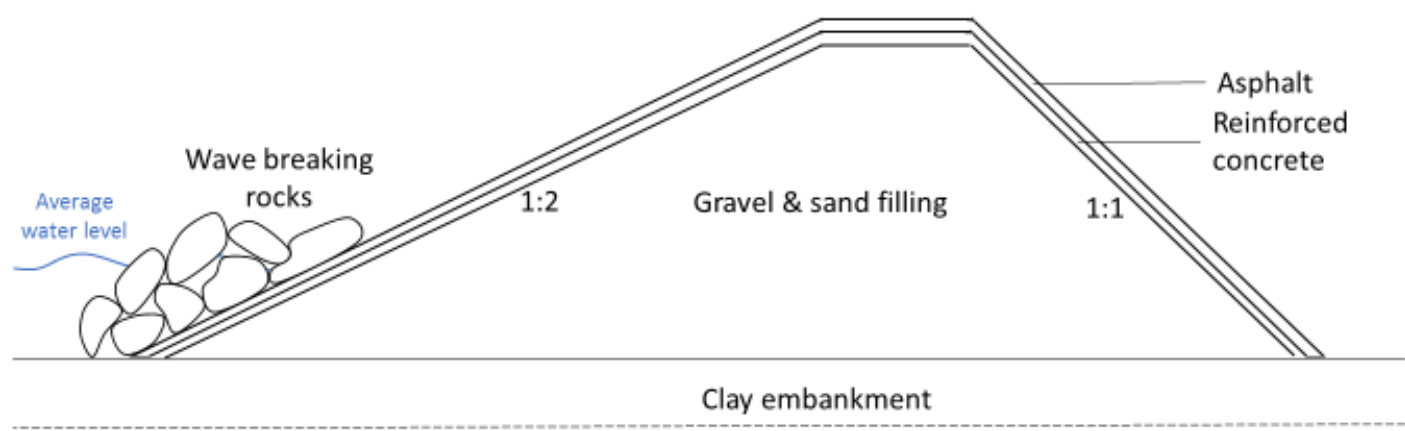

(b)

Figure 1 -Designs for the two scenarios modelled in the LCA framework, to fulfill the functional unit: (a) the baseline single-family residence, and (b) the dike.

\subsection{Modelling water levels and sea level rise}

The sea's water levels in the coastal area considered must be modelled and forecasted over a full century, which implies that SLR will be important. Hence, historical data and SLR projections are combined when describing a non-stationary annual maximum series over the relevant time horizon. The choice of an annual maxima series implies that a maximum of one flood event occurs per year.

Historic data are used to describe the sea water level distribution at the start of the time frame considered, given city. 

expected SLR over the projected time horizon, $Z_{\text {city. }}$. As shown by e.g. Grindsted et al (2015) this distribution is in general positively skewed and can be modelled by e.g. a log-normal distribution. The combination of the two stochastic variables, $Y_{\text {city }}$ and $Z_{\text {city }}$, yields the stochastic variable describing the water levels for the next century as a function of time, $X_{t, \text { city. }}$. For each simulation the annual maximum water level for each year, $t$, can then be drawn from the following distribution from year $t_{0}$ to the end of the projection period:

$$
X_{t, c i t y}=Y_{c i t y}+Z_{c i t y} \cdot \frac{\left(t-\mathrm{t}_{0}\right)}{100}
$$

Equation 1

166

The last element needed is the relationship between the sea water level and the number of house flooded, as well as the corresponding flood depths. This relationship can be built using GIS data and is denoted $N_{\text {city }}\left(X_{t, c i t y}\right)$. Also defined here is the flood threshold, $f t_{c i t y}$, which is the sea level above which damage starts to occur and is determined using the same topography analysis. This allows the calculation of the difference between the sea level and the threshold, the flood depth, denoted $F D_{t, \text { city }}$ :

$$
F D_{t, c i t y}=X_{t, c i t y}-f t_{c i t y}
$$

Equation 2

It should be noted that the sea level can be greater than or equal to the threshold, as even a flood depth of Om will sometimes damage a house (USACE, 2006).

\subsection{Modelling damage as a function of water level}

Flood damage is described using depth as an indicator (Zhou et al., 2012). The stage-damage curves traditionally used in the risk assessment field are derived from historical or insurance data and yield results on the spatial resolution level of land uses (Egorova et al., 2008). This resolution is too coarse for the LCA framework which requires detailed reference flows calculations. Therefore, flood damage can instead be assessed on the level corresponding to flooding of one single-family residence. A range of water levels can be linked to the resulting damage on each item e.g. by using the data from the US Army Corp for a flood duration of 24 hours (USACE, 2006). The USACE uses an economic assessment based on expert opinion and was 
adapted for this framework, although any detailed depth-damage relationship could fit in the framework. The adjustment step consisted in converting the economic values into relative values. Each of the 32 items therefore has its own step function with values ranging between 0 and 1 that takes as input flood depth and yields a percentage of damage, denoted $D_{i}\left(F D_{t, c i t y}\right)$.

The assessment of the impact of flooding over a century is assessed in three steps. First, the reference flow for repairing a given item after a flood, $R F_{i}\left(F D_{t, c i t y}\right)$, is calculated as the product of the item's initial quantity and the relative damage arising from the flood depth:

$$
R F_{i}\left(F D_{t, c i t y}\right)=D_{i}\left(F D_{t, c i t y}\right)_{i} \cdot I Q_{i}
$$

Equation 3

The environmental impact of a storm on house $j, l_{j}\left(X_{t, c i t y}\right)$, is then deduced by multiplying the reference flow by the unitary impact and summing over the 32 items, which is done for all 18 impact categories:

$$
I_{j}\left(F D_{t, c i t y}\right)=\sum_{i=1}^{32} R F_{i}\left(F D_{t, c i t y}\right) \cdot U I_{i}
$$

$$
\text { Lastly, the total impact of flood related repairs in a city over the century considered, } T I_{c i t y} \text {, is calculated by }
$$
summing the impact on all houses affected, for every year of the century:

$$
T I_{\text {city }}=\sum_{t=t_{0}}^{t_{0}+99} \sum_{j=1}^{N_{\text {city }}\left(X_{t, c i t y}\right)} I_{j}\left(F D_{t, c i t y}\right)
$$

The distribution of $T I_{\text {city }}$ is assessed by running 10000 realizations in the Monte Carlo framework. In the practical implementation of the calculations of $T I_{c i t y}$, the flooded residential area was divided into four subgroups of houses which to account for the fact that not all houses have the same flood depth for a given sea level. For example, if the maximum sea level in a given year is $2.10 \mathrm{~m}$ and damage starts to occur at 1.50 $\mathrm{m}$ the maximum flood level is $0.60 \mathrm{~m}$. In this case subgroups are formed for houses flooded at $0.00 \mathrm{~m}, 0.20$ $\mathrm{m}, 0.40 \mathrm{~m}$ and $0.60 \mathrm{~m}$. It has been validated that the division into subgroups does not change the statistical properties of $T I_{\text {city. }}$. 
The 10000 iterations of $T I_{c i t y}$ are then analyzed by choosing a mathematical distribution that is best fitted.

207 This is done using the @Risk software (Palisade, 2018) and its distribution fitting function which tests fourteen 208 typical distributions (e.g. exponential, inverse gaussian, log-normal or Weibull) and ranks them according to 209 their Akaike information criterion. This distribution is then used to calculate the two metrics defined in section 2.1 .

\subsection{Modelling relative efficiency}

To help interpreting the results yielded, a communicative indicator measuring the relative efficiency of a dike is defined. This equation yields the maximum length of dike that can be used to protect one house in the catchment and still have the dike as the favorable scenario. When compared to the observed value, which is the ratio of the dike length and the number of houses it protects, it shows whether the dike is a viable scenario and how it performs. The relative efficiency, RE, is hence the ratio of the average impact of flood related repairs per house protected and the impact of the dike per meter:

$$
R E=\frac{\overline{T I_{\text {clty }}} / \overline{M_{\text {clty }}}}{d i_{\text {city }} / d l_{\text {city }}}
$$

Equation 6

219

where $\overline{T I_{\text {clty }}}$ is the mean of the total impact over the 10000 simulations and $\overline{M_{\text {clty }}}$ is the mean number of houses protected by a dike in a city, found by counting all houses flooded at least once in the century, also averaged over all simulations.

\subsection{Assessing sensitivity}

To analyze the robustness of the model, a sensitivity analysis is conducted, starting by a perturbation analysis. Selected key parameters are made to vary in a likely range and the effect of that change on the results is expressed using sensitivity ratios calculated via Equation 7 . For example, a ratio of 0.2 means that the relative change in results is $20 \%$ of the relative change in parameter. A linear influence of a parameter will therefore be reflected by a value of 1 .

$$
S R=\frac{\frac{\Delta \text { Results }}{\text { Initial result }}}{\frac{\Delta \text { Parameter }}{\text { Initial parameter }}}
$$


The second step of the sensitivity analysis is an assumption check. Three assumptions were challenged 232 to evaluate the influence of the house design, the timing of the dike construction as well as the $\mathrm{LCl}$ modelling principle. A variant on the baseline single family residence was modelled, referred to as summer single-family residence. It is a smaller $100 \mathrm{~m}^{2}$ house built on concrete slab with a wooden structural frame, a thinner $15 \mathrm{~cm}$ thick mineral insulation, and the same 120 years useful life as the baseline single-family residence. It was designed to represent cities, notably in coastal cities, that have different types and usage of houses such as vacations houses. The idea of changing the time frame came from the observation that, for the cases studied, most of the storms occur during the second half of the century studied while the first twenty years are safe. This implies that in general it is recommendable to build the dike twenty years later. Hence this assumption check considers the same scenarios but runs from 2035 to 2135. Finally, the LCl modelling principle chosen was the attributional approach despite forecasts in this study looking a hundred years in the future. The potential influence of a consequential framework had to be investigated.

\subsection{Inter-category correlation}

The LCA methodology utilized is ReCiPe, which includes 18 impact categories. To make the results clearer, the number of categories displayed was reduced by assessing the correlation between categories (Laurent et al., 2018). This allowed to represent the behavior of all the results while presenting a reduced number of impact categories. A correlation was confirmed between two categories when the correlation coefficient was above $99.9 \%$.

\subsection{Considered cases}

Three case studies were assessed by using the proposed framework. Copenhagen, Frederiksværk, and Esbjerg have been selected in an attempt to represent the three typical flooding zones that can be found in Denmark, as illustrated by Figure 2. The two characteristics defining these zones are: 1) flood hazards in the form of frequency of extreme water levels causing damage and topography, and 2) urban density.

To model the present $\left(Y_{\text {city }}\right)$ and forecasted water levels $\left(Z_{\text {city }}\right)$, historical data from Danish meteorological stations (Danish Coastal Authority, 2012) and SLR projection under RCP 8.5 (Grinsted et al., 2015) were used (cf. section 2.4). In the case of Copenhagen, data from a flood protection plan (COWI, 2017) was used to model events with a return period higher than 10 years. Figure 3 shows two example of the stochastic variable $X_{t, c i t y}$ for each case, by representing the present water level distributions and an example of forecasted water 
levels for the end of the century. The GIS data needed to determine the relationship between sea water level and flood depth, $N_{\text {city }}\left(X_{t, c i t y}\right)$, was downloaded from the Danish portal for Climate Change Adaptation 261 (Miljøstyrelsen, 2017). The resulting functions are displayed on Figure 4. Using the same topography analysis, damage threshold for Copenhagen, Frederiksværk, and Esbjerg were determined to be 1.5, 1.6 and 3.8m, respectively.

Moreover, it should be noted that the term coastal area in the functional unit is purposefully vague. Said area is defined independently for each of these case studies depending on the topography of the areas and hence what areas and houses are affected. This leads to different sizes of area protected, numbers of houses included (cf. Figure 4) and dike characteristics. In Copenhagen, Frederiksværk and Esbjerg respectively, the parameters is investigated in the sensitivity analysis (cf. section 3.3.1).

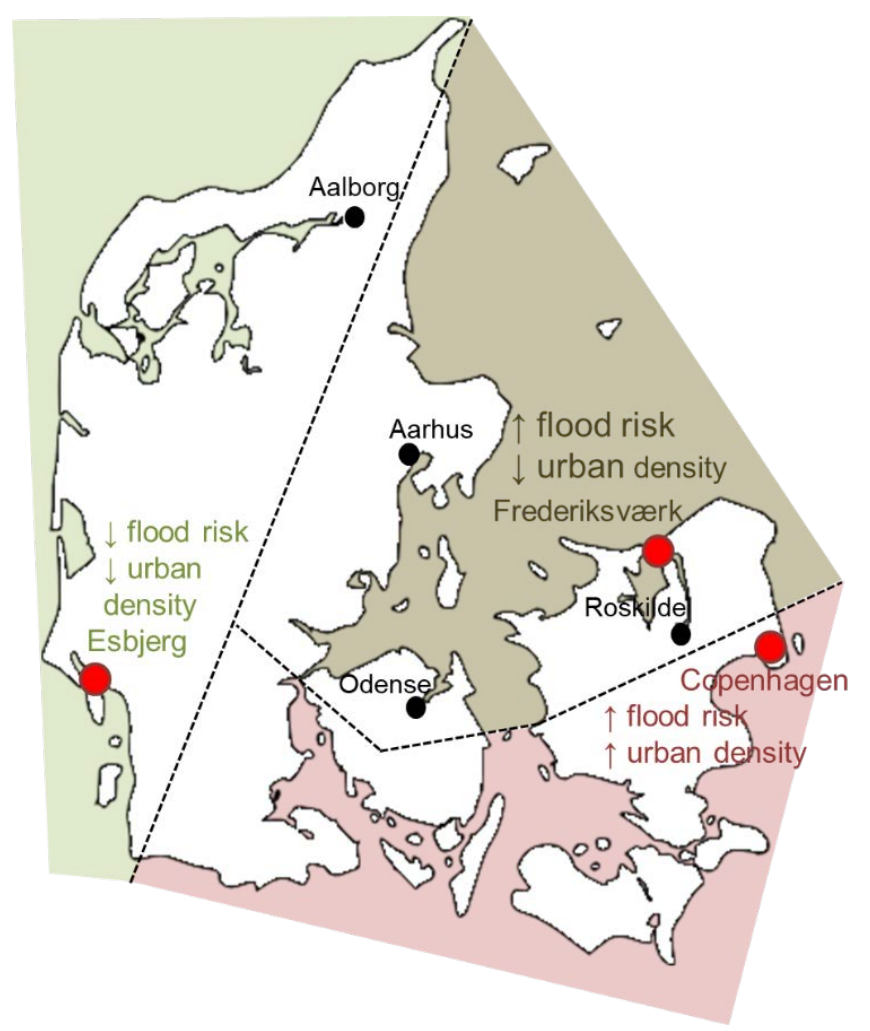




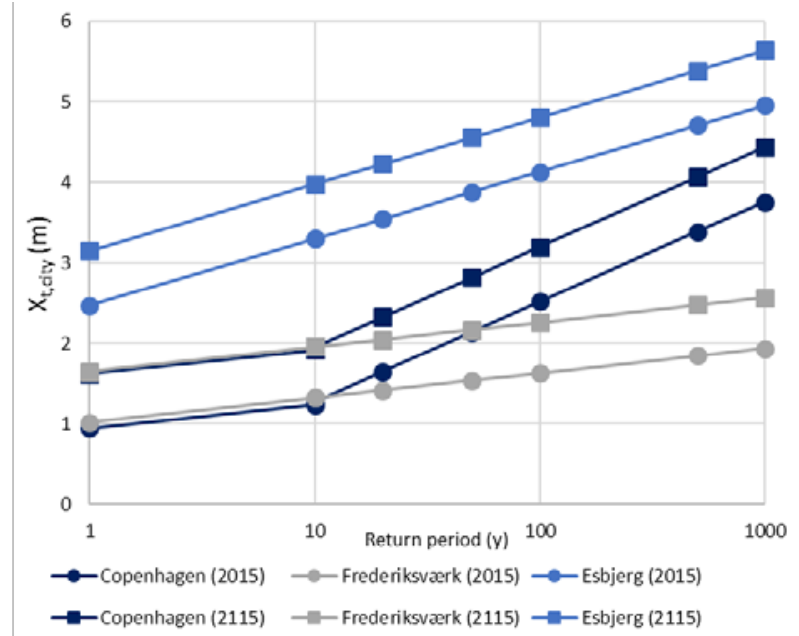

Figure 3 - Water levels distribution for the three cases with an illustration of the effect of $S L R$

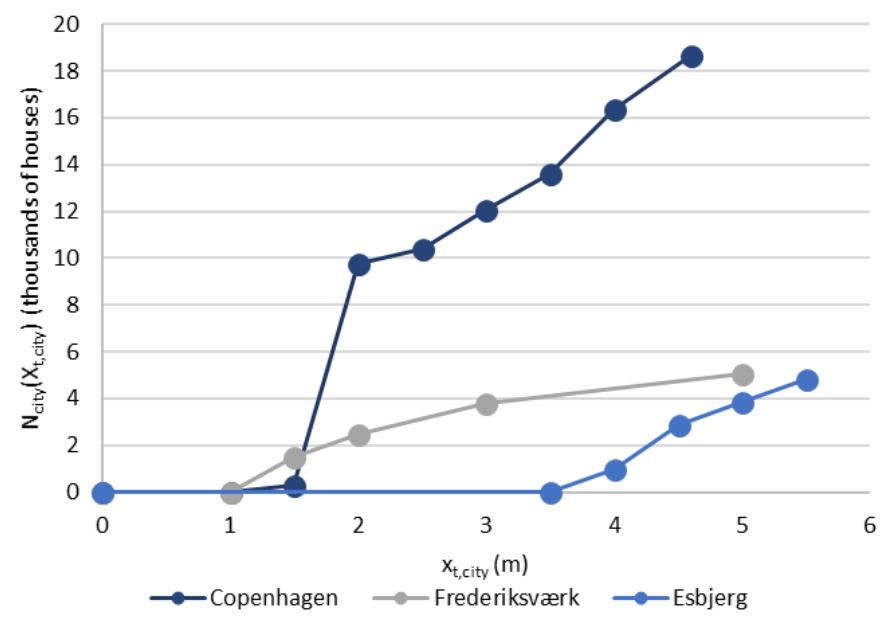

Figure 4 - Relationship between flood depth and damage for the three cases

\section{Results}

The results for the three case studies are presented in the following section. It should be noted that these case studies are three separate examples of the application of the framework developed in this paper. Comparison between the cases are to be made with care. Moreover, after studying inter-category correlations (see section 2.8), it was found that only seven impact categories out of ReCiPe's eighteen need to be displayed. Climate change is representative of ozone depletion, terrestrial acidification, photochemical oxidant formation, particulate matter formation, ionising radiation, water depletion, and fossil depletion. Marine eutrophication is representative of terrestrial ecotoxicity. Freshwater ecotoxicity is representative of freshwater eutrophication, human toxicity, freshwater ecotoxicity, and marine ecotoxicity. And finally, agricultural land occupation, urban land occupation, natural land transformation, and metal depletion all represent themselves as no correlation could be found. It was chosen to present the normalized LCA results in the following section wherever relevant. They are calculated by dividing the LCA scores by a reference score. Here the emission or resource share of an average European individual over one year is used as the reference score. Thus, the normalized result represent the number of annual personal budget occupied by the project.

\subsection{Metric 1, normalized mean impacts}

To better showcase what is compared each time the two scenarios are evaluated, the normalized impact on climate change of both scenarios in Esbjerg are shown in more detailed through Figure 5. The results are 
shown on the level of the items and materials constituting the houses and the dike. Esbjerg was chosen because the two scenarios' impacts on climate change are close, making the comparison easier.

The distribution of impact in the flood related repairs scenario is largely different from what could be found in classical LCAs of houses. Indeed, what is assessed here is not the impact of the items in the context of the life cycle of a house, but in the context of flooding. Moreover, this distribution would vary if Figure 5 depicted the situation in Copenhagen instead of Esbjerg. Indeed, the average and variance of the flood depth in Esbjerg are higher than in Copenhagen. If Copenhagen was considered, it would result in less damage to structural elements such as the structural frame which is damaged only at higher flood depth (USACE, 2006), which would in turn lead the structural frame to be proportionally less impactful.

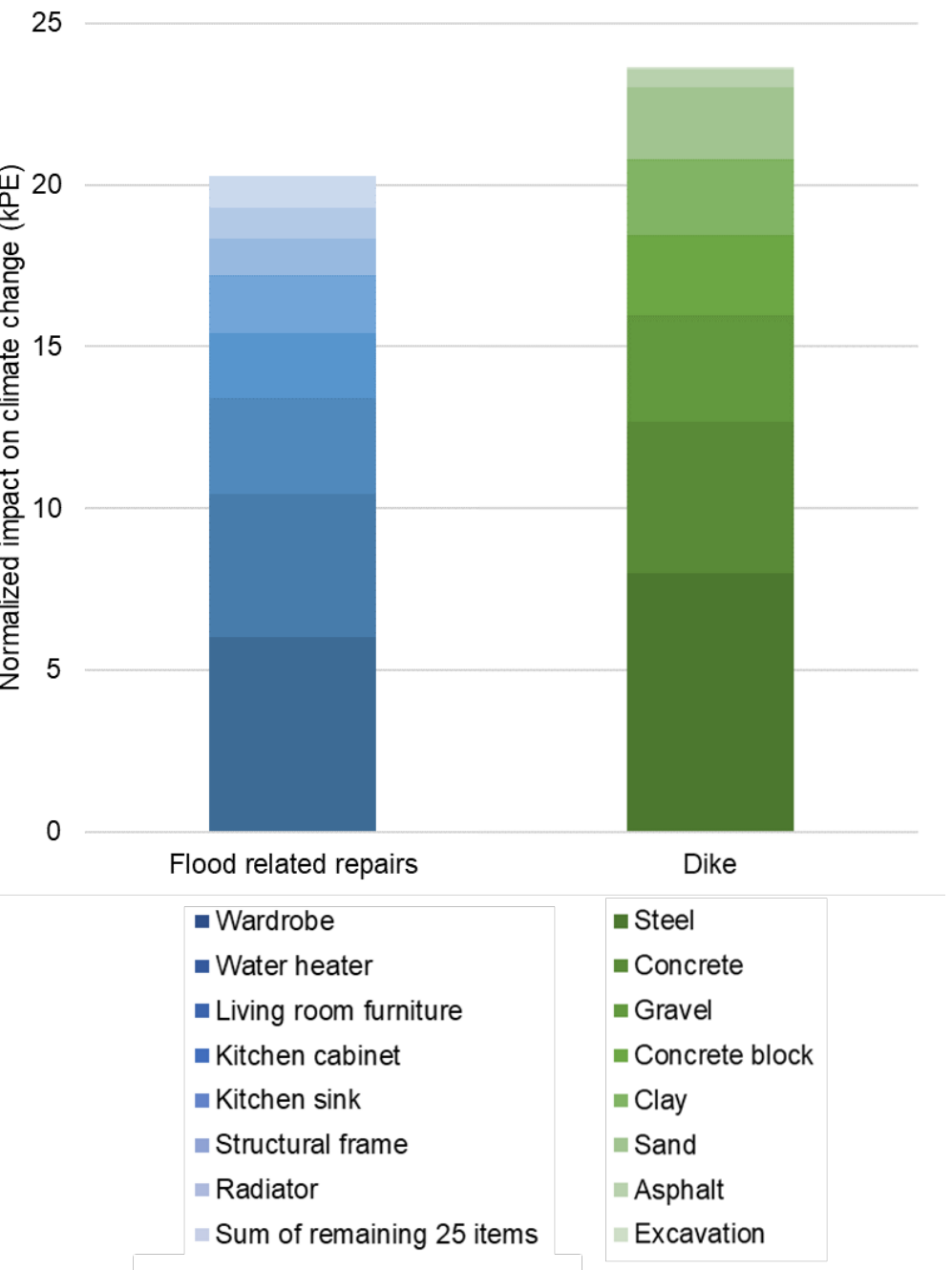

\footnotetext{
Figure 5 - Normalized impact on climate change in thousand PE (KPE) for both scenarios in Esbjerg, divided by items or materials constituting each solution.
}

Figure 6 provides an overview of the results through a comparison between the average normalized impact of flood related repairs and of the dike's construction across all impact categories. It shows that the 
normalized impact on climate change of flood related repairs in Copenhagen, Frederiksværk and Esbjerg is 261, 52.4 and 20.3 kPE while the fixed impact of the respective dikes is $5.78,9.95$ and $23.6 \mathrm{kPE}$. Using this metric, it is indicated that a dike is highly favorable in Copenhagen, preferable in Frederiksværk, and that the impact is the same in Esbjerg.

The dike in Copenhagen protects a population of approx. 30 thousand inhabitants (when counting 2.3 inhabitant per house) during one hundred years, equivalent to one million Person Equivalent (PE). The normalized results illustrated by Figure 6 are, overall, of the order of magnitude of the tens of thousands PE. This means that, roughly, $1 \%$ of the environmental budget of one individual living in the flood prone zone of Copenhagen are spent protecting against flooding.

With this first overview, some categories exhibit a different behavior than other which can be scrutinized. The gap between the two scenarios' impact on agricultural land occupation is wide due to the collection of wood needed for the flooring and siding of the houses, two items rapidly damaged by surges. On the other hand, this gap is narrow for urban land occupation and natural land transformation due to the high impact of the gravel needed for the dike filling and the clay needed for its embankment. It is also narrow for metal depletion due to the high amount of steel needed to reinforce the dike cover's concrete.

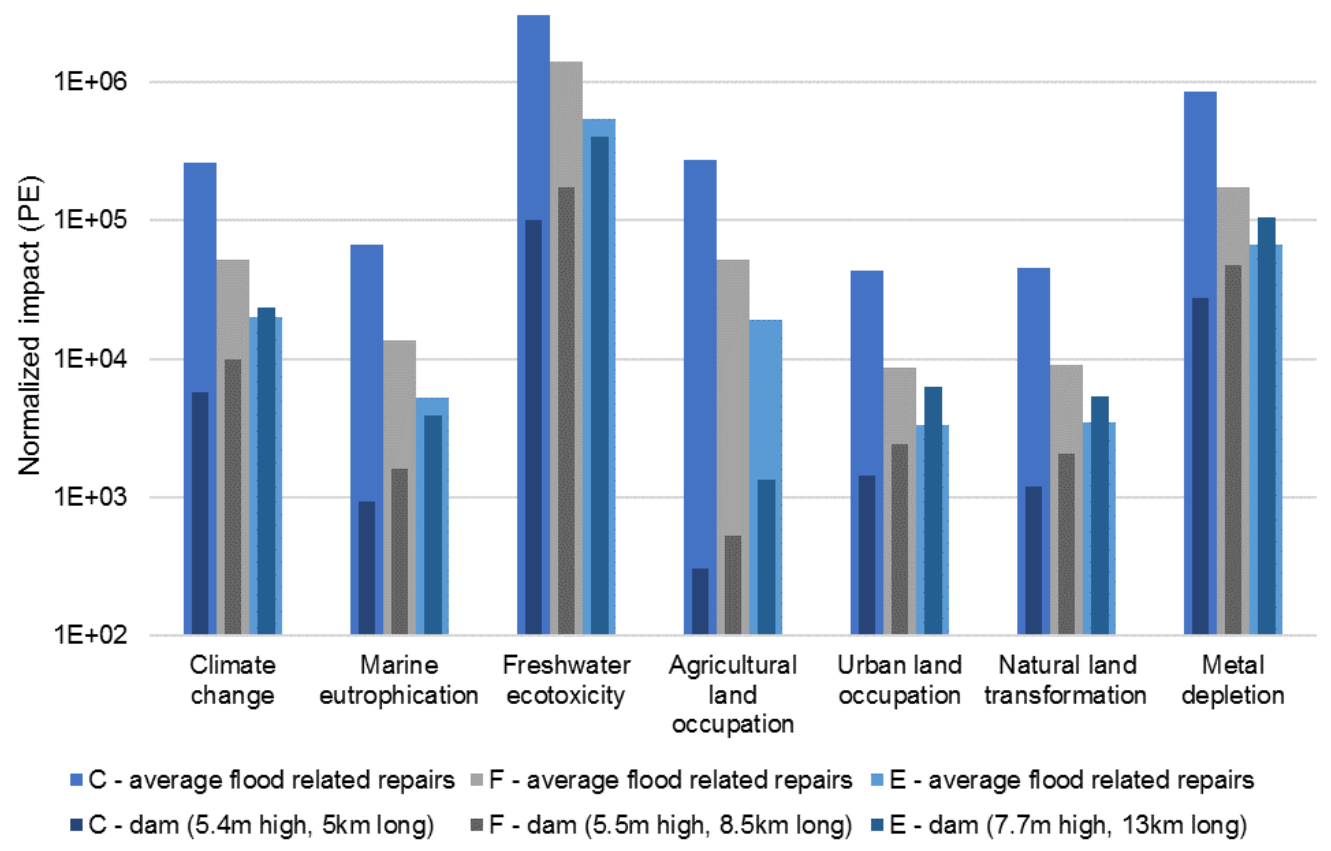

Figure 6 - Normalized mean results for the flood related repairs, and the dam construction in the selected categories, for Copenhagen (C), Frederiksværk (F), and Esbjerg (E) where the results for the three separate case studies are not to be compared directly. Note that the impacts are shown on a log scale.

3.2. Metric 2, probability of dike being most efficient 

of occurrences of floods. On the contrary, Figure 6 shows the fitted cumulative probability and the deterministic dike impact in the case of Frederiksværk, using normalized impacts on climate change. In this case, it can be graphically estimated by identifying the break event point that there is $80 \%$ chance that building the dike yields less environmental impact on climate change than repairing the houses after floods occur in the residential sector.

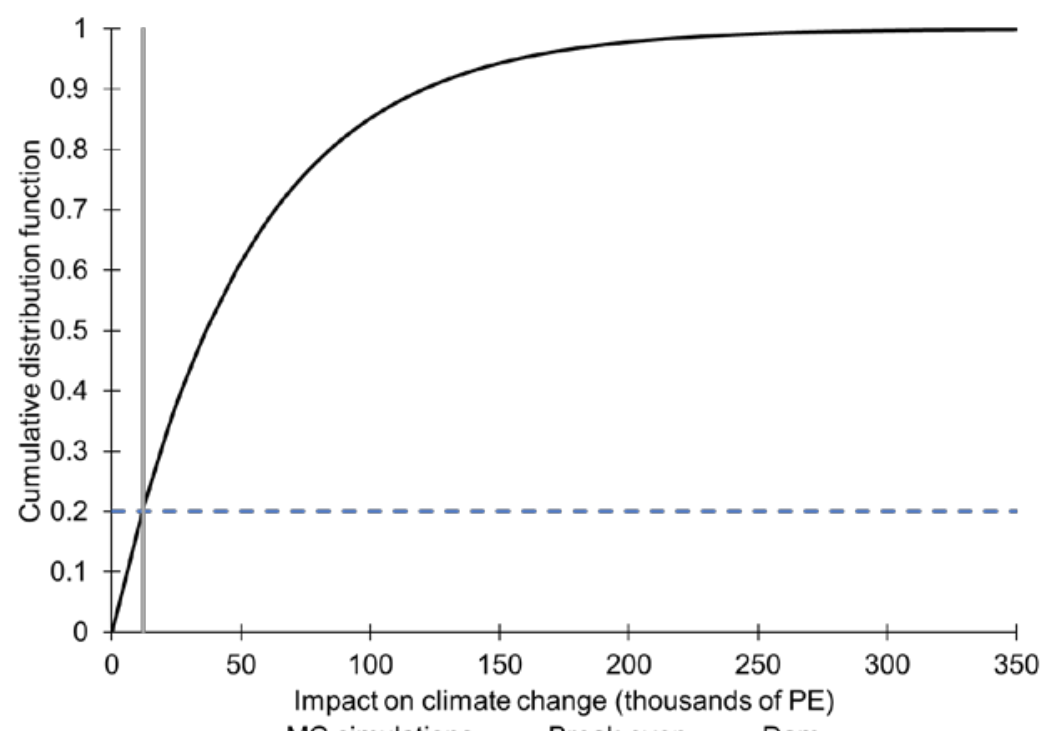

Figure 7-Fitted cumulative probability of the repair's normalized impact on climate change in Frederiksværk yielded by Equation 5 plotted against the deterministic impact of constructing a dike.

Following the methodology illustrated by Figure 6, the probability that flood related repairs have a higher impact than building the dike was calculated for the selected impact categories as shown on Figure 7 . The first observation is that, disregarding the impact category considered, the construction of a dike in Copenhagen seems very favorable since all simulations indicate that the dike is the better of the two scenarios. This is due to the previously identified high flood risk which manifests as an average of 37 storms damaging up to 13 thousand houses in the considered area of Copenhagen, mostly towards the end of the century. The results for the other two cases are less straightforward. On average in impact categories, building a dike has $85 \%$ chances to be the environmentally better choice in Frederiksværk and only 32\% in Esbjerg. 


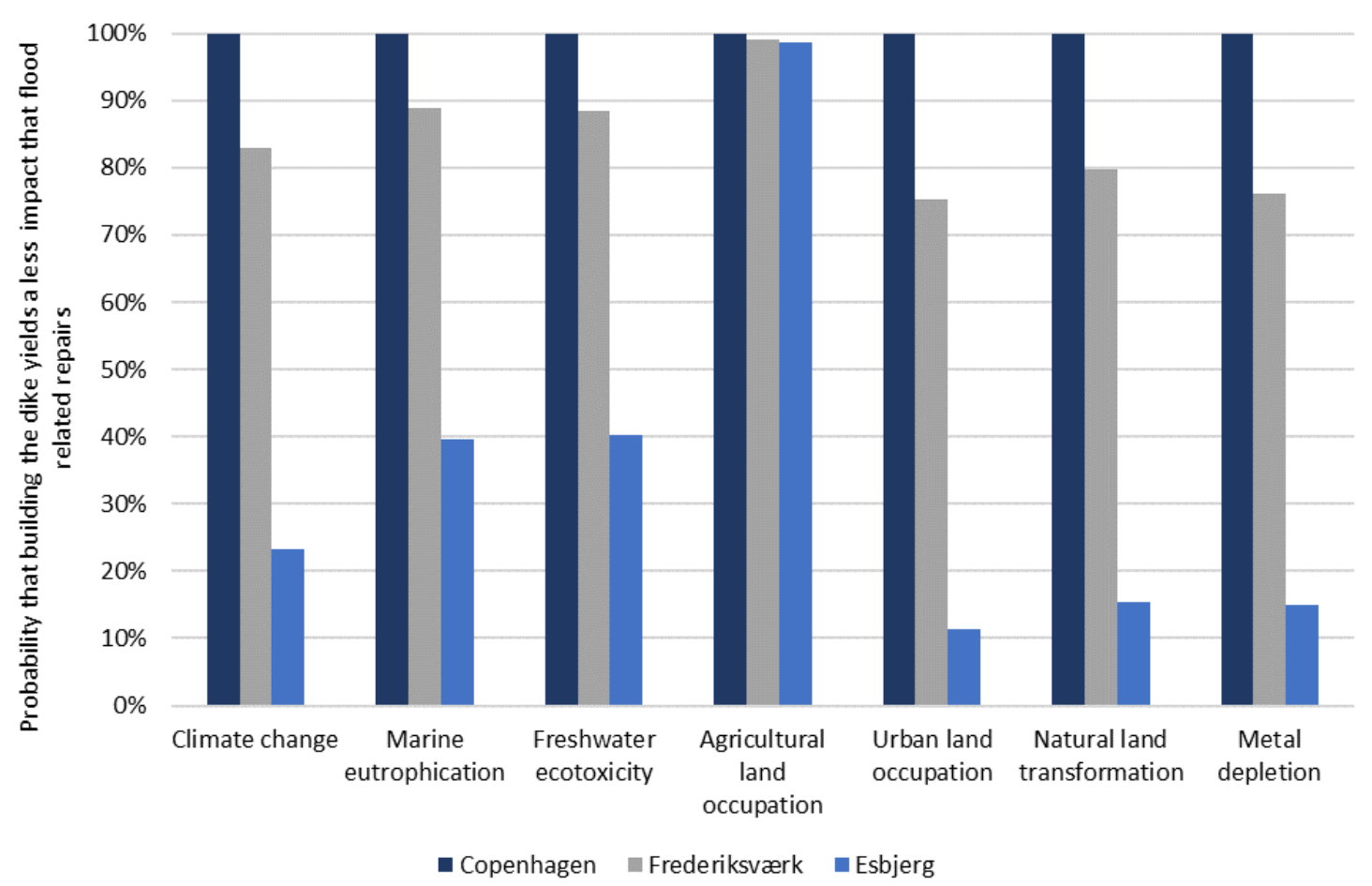

Figure 8 - Probability that building the dike yields less environmental impact than flood related repairs of the residential sector

\subsection{Relative efficiency of dike}

Figure 8 shows the calculated and observed relative efficiencies of the dikes, calculated using Equation

6. By looking at the observed indicators, it can be deduced that the dike in Copenhagen is by far the one performing the best because it protects numerous houses and is relatively short. In Frederiksværk and Esbjerg, the dikes are longer and protect less dense urban areas, therefore rendering them less efficient as they both require close to four meters of dike to protect a single house. As an element of comparison, the dike in Frederiksværk is nine times less efficient than the one in Copenhagen. The other side of this issue, related to hazard, is unveiled by the calculated indicators and depends on the impact category considered. The higher the flood risk per house, the higher the calculated indicator will be. Moreover, the wider the gap between observed and calculated RE, the more margin there is for dike design. Copenhagen has the widest gap and therefore there is the largest margin for designing. Indeed, assuming it would protect the same area, the dike could be thrice as high and twice as long and still have $81 \%$ chance to yield a positive environmental bill for climate change. 


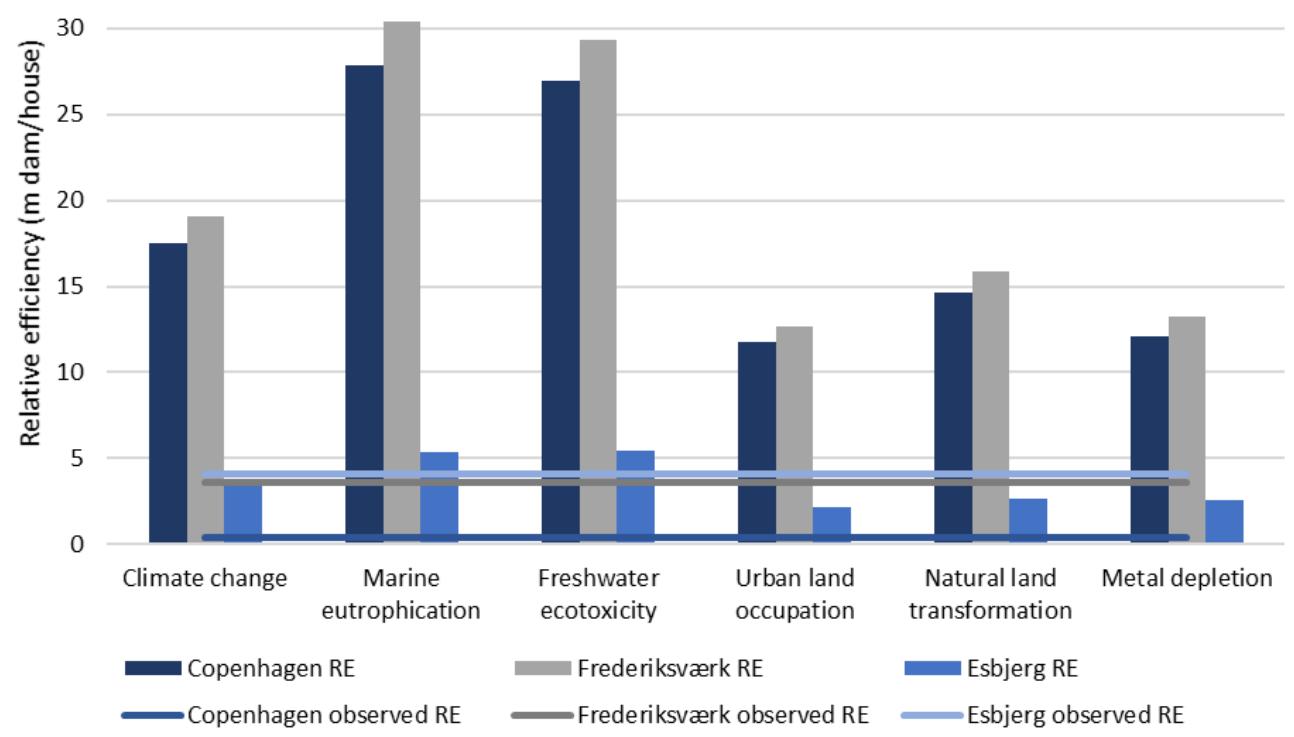

Figure 9 - Comparison between the observed and the calculated relative efficiencies, RE (cf. Equation 6)

\subsubsection{Perturbation analysis}

Including climatic changes of the sea level leads to high levels of uncertainty. To assess the robustness 363 of the model and identify the influence of key parameters on the results, a perturbation analysis was conducted. 364 The sensitivity ratios, calculated using Equation 7, are reported in Figure 9. The values displayed are the 365 average of the sensitivity ratios across the 18 impact categories as well as the $\mathrm{min} / \mathrm{max}$ ranges. The 366 characterized results for Frederiksværk were chosen as a reference point as it is the most disputable case of the three.

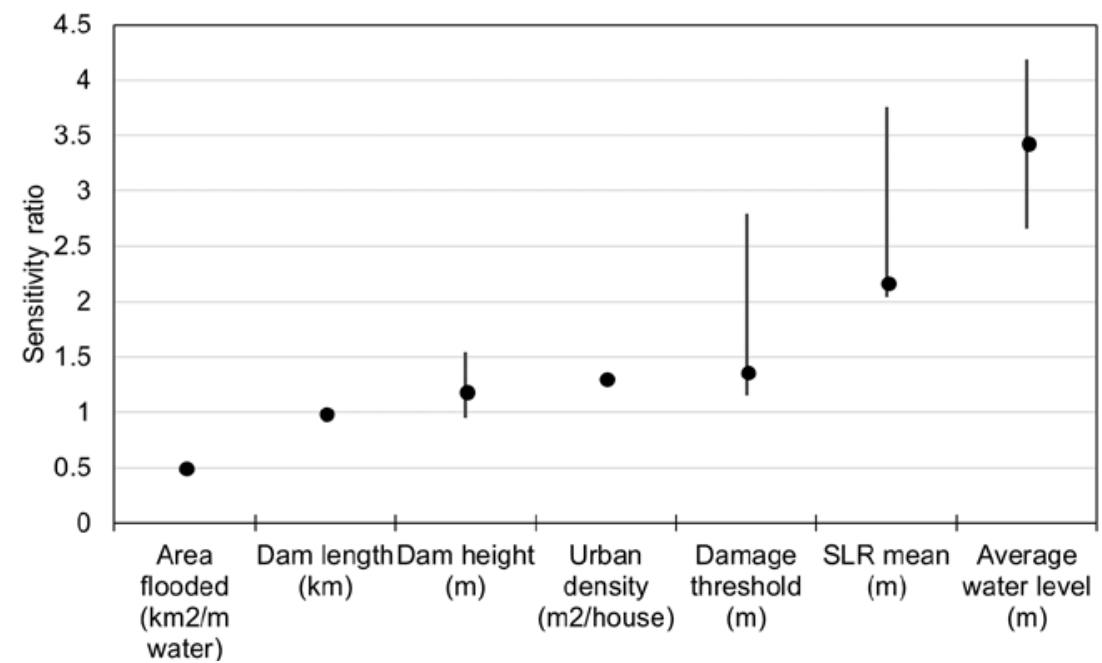


The sensitivity parameters do not indicate an impact that jeopardizes the overall conclusions of the study. Still the ratios are high, meaning that the results are responsive to changes in these overarching parameters. The parameters with the highest ratios are the average water level and the SLR mean. It demonstrates the importance of precise historical data and their statistical analysis ensuring proper modelling of water levels both of today and of likely future changes. The aim of the Monte Carlo analysis was precisely to account for that expected large sensitivity by modelling both these parameters stochastically.

Then comes the damage threshold, the water level at which damage starts to be accounted for. The value for Frederiksværk has been set at $1.6 \mathrm{~m}$, even though urban surfaces start to get flooded as soon as $1 \mathrm{~m}$ (cf. Figure 4). However, during the first $60 \mathrm{~cm}$, the water only hits a swampy area of the city while the residential zone stays safe. This highlights the fact that any urban development in that area comes with a great risk, and construction permits should only be granted with great care. The same observation is true for the harbor area of Esbjerg. The significant ratio for the urban density points in the same direction, unveiling the importance of careful urban planning and adjustments on urban density according to risk.

The ratios of the dike's height and length demonstrate that designers of this hard solution should make plans and adjust the protection level with parsimony. Finally, while the sensitivity of the results to changes in the area damage factor is relatively lower, it still emphasizes the influence of the hydrological models used to visualize the water progression in cities.

\subsubsection{Assumption check}

Figure 10 shows the results of the assumption check as discussed in section 2.6, using the probability that building the dike yields less impact than flood related repairs (cf. Figure 6), where Frederiksværk was once again taken as a reference. It shows that house design matters and demonstrates that final conclusions depend on the type of houses that are in the residential sector protected by the dam. The case study areas are vastly dominated by single-family houses and hence the choice of only one type of house can be justified; however, the assumption check seems to indicate that in general several types of buildings should be included in the analysis. A striking result is the one for the change of time frame where the balance significantly tilts in favor of building the dam, simply by delaying its construction by twenty years. This finding is momentous as it proves how crucial it is to time action plans accurately when it comes to climate change adaptation. Finally, the results go up in average by $1 \%$ when the modelling framework is changed from attributional to 
consequential. Amongst the house's items, the main variations in impact when changing the modelling framework were found for the toilet, bathroom sink, wooden baseboard, sheetrock, and ceramic tile.

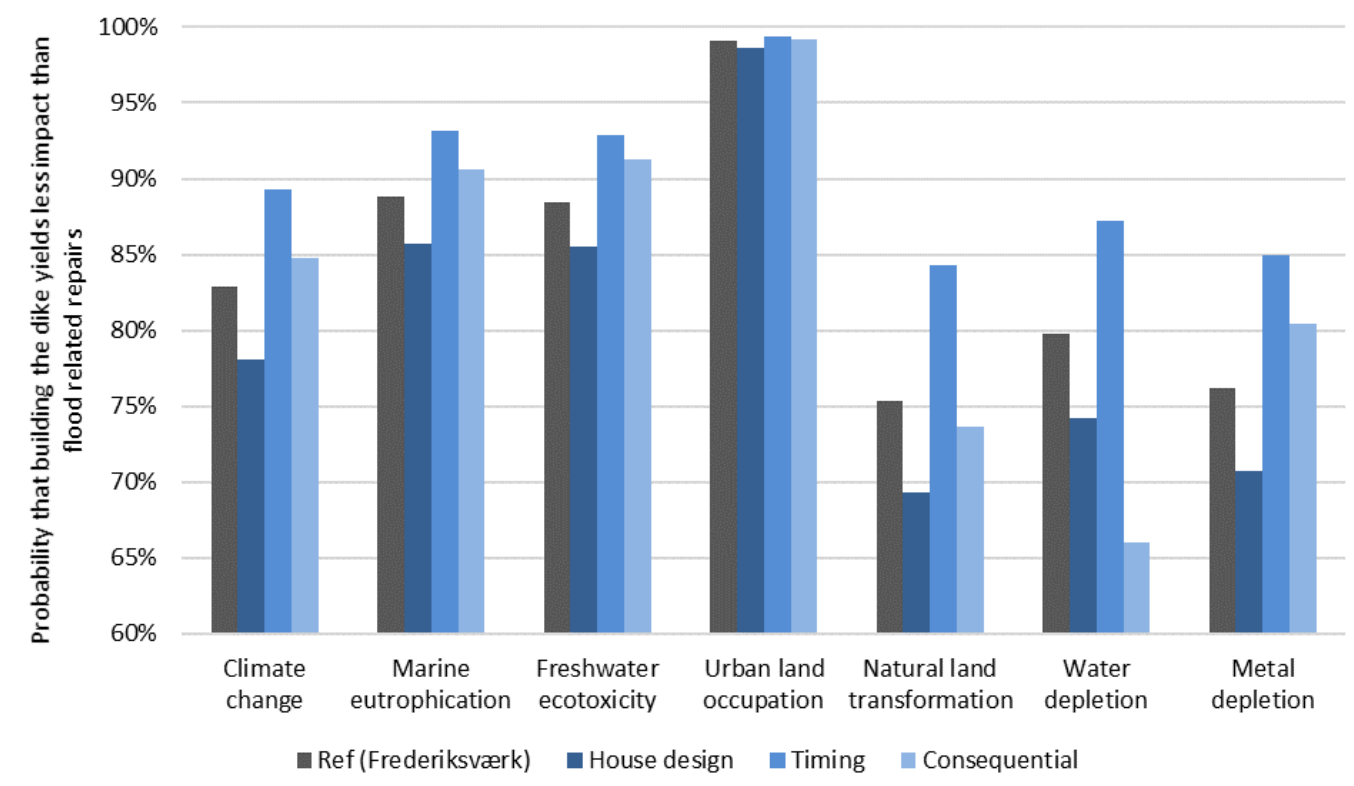

Figure 11 - Scenario analysis with Frederiksværk as a reference, showing the probability that building the dike yields less environmental impact than flood related repairs

\section{Discussion}

The study has demonstrated how specific combinations of flood risk and flood protection can be analyzed to find optimal scenarios in terms of resource consumption. The purpose has been to demonstrate the potential for such studies rather than obtaining concrete results for the three study sites.

One important constraint in the present study is that urban development has not been considered. The extension is in principle straight forward, by allowing the relationship between flood depth and damage to vary as a function of time just like the water level distribution does. This would mean that both scenarios are dominated by aleatory uncertainty and introduce a high correlation between the two scenarios, because the urban development would be an important co-variate. Furthermore, urban development is typically decided by the same authorities who decide on whether to construct a dam or not which was in the end the reason why this option was selected. However, the importance of this constraint can be illustrated by the case study in Frederiksværk, where the urban zone contains large areas that will be flooded when the sea water level reaches $1.0 \mathrm{~m}$. No houses are placed in these locations and, as a result, the impact of flooding up to $1.6 \mathrm{~m}$ is set to zero. If the low lying urban areas were fully developed, the result of the study would show that a dike 
was highly recommendable for the region. Hence the feasibility of building a dike depends much on past decisions on urban development and spatial planning can and should also be considered when taking decisions on where and how to build dikes. Moreover, in that urban landscape, only the residential sector was modelled. Even though it is the sector with the highest impact (Huizinga, 2007), a more complicated setup is needed in areas where the land use is not homogeneous..

The long useful life of the dike examined entails for a lengthy time frame of a century. While necessary, this comes to the price of a lowered technological and temporal representativeness. It is indeed assumed that throughout this 100 years, the houses will be repaired using today's state of the art. On the contrary, a high geographical fidelity is achieved by the choice of precise field cases and through the ways the Life Cycle Inventories (LCls) of the different items were built.

Moreover, using maximum flood depth as an indicator for flood damage is criticized because it is oblivious to factors such as flood velocity and duration or to failures occurring when structures are lifted (Huizinga, 2007; Middelmann-Fernandes, 2010; Pistrika and Jonkman, 2010). In this study, the upper validity limit of the water level range is around 4m, to avoid the uncertainty linked to high velocity waters (Middelmann-Fernandes, 2010; USACE, 2006). While some outliers of the stochastic analysis fall outside of this boundary, they are statistically insignificant, appearing in less than $1 \%$ of the simulations for the three cases. Adding the fact that flood damage is assessed on the item level, it is argued that this approach mitigates the limitations of stage-damage curves while fitting in the LCA framework.

\section{Conclusion}

This study has presented a new methodology for a resource-based approach for flood risk management consisting in a comparative LCA where the flood risk impact is assessed by means of a Monte Carlo analysis. It allowed to compare the environmental impact of building a dike to protect a coastal area against the alternative of repairing the residential area after each flood. The stochastic approach accounted for climate change adaptation and dealt with the high uncertainty tied to sea water level forecasting. Three Danish case studies were assessed using the integrated method.

The main conclusions of this enterprise are summarized here:

- When assessing the environmental impact of flood damage, the high uncertainty of predicting the number and timing of sea surge extremes requires a probabilistic approach. Both present and future water levels should be modelled as stochastic variables as they are the main factors introducing uncertainty. LCA is a 
resilient framework for environmental assessment that was able to incorporate a non-traditional Monte Carlo analysis while maintaining consistency.

- The case studies indicate that in a densely populated area with moderate flood risk, the construction of a dike is certain to have less impact than flood related repairs of the residential sector. In less densely populated areas with lower flood risk the dike in general has the highest impact.

- After the modelling of water levels, the major factors influencing the results of this study are the topography analysis, the timing of the dike's construction, and its characteristics. The influence of the topography analysis highlights the importance of precise GIS data and corroborates the previous comment made on urban development.

The main limitation of this study is the assumption of a fixed urban landscape. No urban development or evolution in construction's state of the art were assumed. The method can be extended to account for such changes, but for the case study areas no detailed planning was available and the introduction of correlation between the scenarios makes a simple comparison difficult. It is believed that a fresh perspective is offered by assessing this wicked urban planning issue from an environmental point of view, rather than an economic. Taking a step back, a number of interesting openings appear beyond the direct results. It is shown for example that further urban development in flood prone areas is, to say the least, a questionable choice and should only be made with great care. It also illustrates that, while hard solutions such as dikes are sometimes needed because of the relative urgency of the situation, softer and less impactful solutions should be considered first. Notably if the results are ambiguous it is a clear call for taking action on spatial planning because otherwise the dike will become more and more favorable as time evolves.

Competing interests statement: The authors have no competing interests to declare.

\section{References}

Brudler, S., Arnbjerg-Nielsen, K., Hauschild, M.Z., Rygaard, M., 2016. Life cycle assessment of stormwater management in the context of climate change adaptation. Water Res. 106, 394-404. https://doi.org/10.1016/j.watres.2016.10.024

COWI, 2017. Opdateret Overslag For Sikring Af København Mod Stormflod.

Danish Coastal Authority, 2012. Højvandsstatistikker.

DPWH, JICA, 2010. Technical standards and guidelines for design of flood control structures.

Egorova, R., van Noortwijk, J.M., Holterman, S.R., 2008. Uncertainty in flood damage estimation. Int. J. River Basin Manag. 6, 139-148. https://doi.org/10.1080/15715124.2008.9635343 
European Commission, 2007. Directive 2007/60/EC Of The European Parliament And Of The Council on the assessment and management of flood risks, Official Journal of the European Parliament.

Flynn, K.M., Traver, R.G., 2013. Green infrastructure life cycle assessment: A bio-infiltration case study. Ecol. Eng. 55, 9-22. https://doi.org/10.1016/j.ecoleng.2013.01.004

FME, 2016. Database ÖKOBAUDAT [WWW Document]. URL http://www.oekobaudat.de/en/database/database-oekobaudat.html (accessed 2.10.17).

Goedkoop, M., Heijungs, R., De Schryver, A., Struijs, J., van Zelm, R., 2013. ReCiPe 2008, A life cycle impact

Goldstein, B., Rasmussen, F.N., Goldstein, B., Rasmussen, F.N., 2018. LCA of Buildings and the Built Environment, in: Life Cycle Assessment. https://doi.org/10.1007/978-3-319-56475-3_28

Grinsted, A., Jevrejeva, S., Riva, R.E.M., Dahl-Jensen, D., 2015. Sea level rise projections for Northern Europe under RCP8.5. Clim. Res. 64, 15-23. https://doi.org/10.3354/cr01309

Guha-Sapir, D., 2016. 2016 preliminary data1: Human impact of natural disasters.

Hallegatte, S., Green, C., Nicholls, R.J., Corfee-Morlot, J., 2013. Future flood losses in major coastal cities. Nat. Clim. Chang. 3, 802-806. https://doi.org/10.1038/nclimate1979

Hennequin, T., Sørup, H.J.D., Dong, Y., Arnbjerg-Nielsen, K., n.d. Life Cycle Assessment (LCA) of a typical European single-family residence and its flood related repairs. Build. Environ.

Hirabayashi, Y., Mahendran, R., Koirala, S., Konoshima, L., Yamazaki, D., Watanabe, S., Kim, H., Kanae, S., 2013. Global flood risk under climate change. Nat. Clim. Chang. 3, 816-821. https://doi.org/10.1038/nclimate1911

Huizinga, H., 2007. Flood damage functions for EU member states.

ICPR, 2001. Atlas der Uberschwemmungsgefährdung und möglichen Schäden bei Extremhochwasser am Rhein. International Commission for the Protection of the Rhine River.

INIES, 2017. Inventaires de cycle de vie [WWW Document]. URL http://www.inies.fr/inventaires-de-cyclede-vie/ (accessed 3.10.17).

ISO, 2006a. EN ISO 14040:2006 - Environmental management - Life cycle assessment - Principles and framework. https://doi.org/10.1136/bmj.332.7550.1107

ISO, 2006b. EN ISO 14044:2006 -Environmental management - Life cycle assessment - Requirements and guidelines. https://doi.org/10.1007/s11367-011-0297-3

Khasreen, M.M., Banfill, P.F.G., Menzies, G.F., 2009. Life-cycle assessment and the environmental impact of buildings: A review. Sustainability 1, 674-701. https://doi.org/10.3390/su1030674

Laurent, A., Espinosa, N., Hauschild, M.Z., 2018. LCA of Energy Systems, in: Life Cycle Assessment. Springer International Publishing, Cham, pp. 633-668. https://doi.org/10.1007/978-3-319-56475-3_26

Lo, S.-C., Ma, H.-W., Lo, S.-L., 2005. Quantifying and reducing uncertainty in life cycle assessment using the Bayesian Monte Carlo method. Sci. Total Environ. 340, 23-33. https://doi.org/http://dx.doi.org/10.1016/j.scitotenv.2004.08.020

MARD, 2011. Technical Guidelines on sea dikes design.

Matthews, E., Friedland, C.J., Orooji, F., Turner, B.S., 2016. Optimization of Sustainability and Flood Hazard 
Resilience for Home Designs. Procedia Eng. 145, 525-531. https://doi.org/10.1016/j.proeng.2016.04.040

Mattila, T., Leskinen, P., Soimakallio, S., Sironen, S., 2012. Uncertainty in environmentally conscious decision making: Beer or wine? Int. J. Life Cycle Assess. 17, 696-705. https://doi.org/10.1007/s11367012-0413-z

Merz, B., Kreibich, H., Schwarze, R., Thieken, A., 2010. Review article "Assessment of economic flood damage." Nat. Hazards Earth Syst. Sci. https://doi.org/10.5194/nhess-10-1697-2010

Middelmann-Fernandes, M.H., 2010. Flood damage estimation beyond stage-damage functions: An Australian example. J. Flood Risk Manag. 3, 88-96. https://doi.org/10.1111/j.1753-318X.2009.01058.x

Miljøstyrelsen, 2017. Se Havvand på land [WWW Document]. URL http://www.klimatilpasning.dk/vaerktoejer/havvandpaaland/havvand-paa-land.aspx (accessed 7.27.17).

Morita, M., 2008. Flood risk analysis for determining optimal flood protection levels in urban river management. J. Flood Risk Manag. 1, 142-149. https://doi.org/10.1111/j.1753-318X.2008.00016.x

Palisade, 2018. @RISK [WWW Document]. URL https://www.palisade.com/risk/ (accessed 5.1.18).

Petit-Boix, A., Arahuetes, A., Josa, A., Rieradevall, J., Gabarrell, X., 2016. Are we preventing flood damage eco-efficiently? An integrated method applied to post-disaster emergency actions. Sci. Total Environ. https://doi.org/10.1016/j.scitotenv.2016.12.034

Petit-Boix, A., Sevigné-Itoiz, E., Rojas-Gutierrez, L.A., Barbassa, A.P., Josa, A., Rieradevall, J., Gabarrell, X., 2017. Floods and consequential life cycle assessment: Integrating flood damage into the environmental assessment of stormwater Best Management Practices. J. Clean. Prod. 162, 601-608. https://doi.org/10.1016/j.jclepro.2017.06.047

Pistrika, A.K., Jonkman, S.N., 2010. Damage to residential buildings due to flooding of New Orleans after hurricane Katrina. Nat. Hazards 54, 413-434. https://doi.org/10.1007/s11069-009-9476-y

Reynard, N., Crooks, S., Wilby, R., Kay, A., 2004. Climate change and flood frequency in the UK. 39th Defra Flood Coast. Flood Manag. Conf. 1-12.

UN, 2014. World Urbanization Prospects, UNDESA. https://doi.org/10.4054/DemRes.2005.12.9

USACE, 2006. Depth-Damage Relationships for Structures, Contents, and Vehicles and Content-to-Structure Value Ratios (CSVR) in Support of the Lower Atchafalaya Reevaluation and Morganza to the Gulf.

Vilches, A., Garcia-Martinez, A., Sanchez-Montañes, B., 2016. Life cycle assessment (LCA) of building refurbishment: A literature review. Energy Build. 135, 286-301. https://doi.org/10.1016/j.enbuild.2016.11.042

Zhou, Q., Mikkelsen, P.S., Halsn??s, K., Arnbjerg-nielsen, K., Halsnæs, K., Arnbjerg-nielsen, K., 2012. Framework for economic pluvial flood risk assessment considering climate change effects and adaptation benefits. J. Hydrol. 414-415, 539-549. https://doi.org/10.1016/j.jhydrol.2011.11.031 